\title{
NEONATAL HEARING SCREENING IN A NICU - A RURAL MEDICAL COLLEGE EXPERIENCE
}

Ravi. D, N. K. Balaji ${ }^{2}$, M. Hanumanth Prasad ${ }^{3}$.

1. Associate Professor, Department of E.N.T, Mandya Institute of Medical Sciences, Mandya.

2. Senior Resident, Department of E.N.T, Mandya Institute of Medical Sciences, Mandya.

3. Professor \& HOD, Department of E.N.T, Mandya Institute of Medical Sciences, Mandya.

\section{CORRESPONDING AUTHOR:}

Dr. Balaji N. K,

Senior Resident,

Department of E.N.T

Mandya Institute of Medical Sciences,

Mandya -57140 .

E-mail: drnkbalaji@gmail.com

\section{HOW TO CITE THIS ARTICLE:}

Ravi. D, N. K. Balaji, M. Hanumanth Prasad. "Neonatal Hearing screening in a NICU - A rural medical college experience". Journal of Evolution of Medical and Dental Sciences 2013; Vol2, Issue 26, July 1; Page: 4649-4652.

\begin{abstract}
OBJECTIVE: To determine the incidence of Auditory impairment in the population of New born infants in a Neonatal intensive Care unit of a Tertiary Care centre using Oto-Acoustic Emissions. METHODS: 648 Newborn infants admitted to NICU in paediatric dept between June 2011 to May 2012 were taken as subjects for the study. OAE testing was done using a Portable OAE device. Each ear was tested separately and interpreted as Pass/Fail depending on the OAE response. RESULTS: Out of 648 infants 613 infants passed the OAE test after the second screening which takes the sensitivity of the test to $94.59 \%$. Out of the 82 infants who failed the test, $22(26.8 \%)$ were preterm with Hyperbilirubinemia, 14(17.07\%) were preterm with respiratory distress, 17 (20.73\%) were preterm only and 29(35.36\%) were term babies. CONCLUSION: Transient Otoacoustic Emissions are a very quick and Noninvasive technique, and suitable for hearing screening in infants. Two-stage screening for hearing improved identification of newborns with hearing loss in a cost effective manner.
\end{abstract}

KEY WORDS: TOAE, Neonatal screening

INTRODUCTION :Bilateral permanent childhood hearing impairment is an important health problem because of its adverse effect on a child's language and communication skills, social and emotional development and educational achievement. ${ }^{1}$ The prevalence of Bilateral permanent childhood hearing impairment of moderate or greater degrees is about 1.2 per 1,000 live births. ${ }^{2}$ The majority of hearing loss is present at birth. ${ }^{2}$ It is believed that the first six months of life is the critical period for language skill acquisition. ${ }^{4}$ Initial evidence, which shows that identification and habituation prior to the age of 6 months improves language and communication, ${ }^{5}$ has to be to be further substantiated by good quality studies. ${ }^{1}$ 
MATERIAL AND METHODS: 648 Newborn infants admitted to NICU in paediatric dept from June 2011 to May 2012 were taken as subjects for the study. OAE testing was done using a Portable OAE device. Each ear was tested separately and interpreted as Pass/Fail depending on the OAE response. Infants who failed the initial test were called for follow up to repeat testing for the second time within 3 months. Infants who failed second test were referred for detailed Audiological evaluation.

RESULTS: 648 high risk infants were screened at the NICU, out of which 370 (57\%) infants were male and 278 (43\%) were females. 525(81\%) infants were born Preterm with LBW, 29(4.5\%) infants were preterm with Hyperbilirubinemia, 23(3.5\%) babies had respiratory distress and remaining $71(11 \%)$ were term babies with high risk.

566(87.3\%) infants passed the test in the first visit (refer Table 1) and 82(12.7\%) babies failed to respond to $\mathrm{OAE}$ screening who were given a date for follow up within the next 3 months.

Out of the 82 infants who failed the test, 22(26.8\%) were preterm with Hyperbilirubinemia, $14(17.07 \%)$ were preterm with respiratory distress, $17(20.73 \%)$ were preterm only and $29(35.36 \%)$ were term babies.

In 82 infants about 56(68.29\%) turned up for second visit of which 47\% (57.31\%) passed the test and 9 (10.9\%)infants did not respond and they were referred for further Audiological evaluation. 26(31.70\%) infants were lost in the follow up for second visit.

So, out of 648 infants 613 infants passed the OAE test after the second screening which takes the sensitivity of the test to $94.59 \%$.

DISCUSSION: With the advent of easy-to-use electro-physiological screening methods like otoacoustic emission (OAE) and auditory brainstem response, hearing status of very young, or even newborn babies, can be predicted accurately. These neonatal hearing screening tests have higher sensitivity and specificity than infant Distraction Test. ${ }^{9}$ OAEs are sounds generated by outer hair cells housed in the cochlea and can be measured in the external ear canal. Detection of OAEs can be hampered by obstructions in the external ear canal and middle ear. Detectable OAEs, therefore, reflect normal function of the auditory pathway as far as the level of the outer hair cells of the cochlea. This technology can be used to detect sensory hearing loss but not retro-cochlear neural dysfunctions. ${ }^{10}$ The technology of OAE has been found to be an effective tool in universal newborn hearing screening. ${ }^{11}$ Since the 1990s, using OAE as newborn hearing screening has become popular in Europe and USA, mainly in birthing hospitals. To date, more than half of the states in the USA have legislation mandating universal hearing screening as a public health programme. ${ }^{12}$

Limitations of OAE Screening

When applied to the newborn, the OAE technique has two major limitations. Firstly, it assesses the hearing pathway as far as the cochlea and any retro-cochlear pathology will be missed. However, retro-cochlear pathologies are expected to be rare in the low-risk babies and therefore the benefit of early detection is uncertain. We therefore consider the OAE technique adequate for routine use in population.

It is well documented that OAE testing has a high false positive rate (up to 15.6\%) in the first 24 hours of life, falling to about $4 \%$ by 72 hours. ${ }^{5,6}$ Although some of this is related to middle ear effusion and debris in the external ear canal, it may also be related to neurological immaturity. 
CONCLUSION: Transient Otoacoustic Emissions are a very quick and Noninvasive technique, and suitable for hearing screening in infants. Two-stage screening for hearing improved identification of newborns with hearing loss in a cost effective manner.

OAE test is an objective, valid and easy-to-use hearing screening tool. It can be performed by enrolled nurses after brief training. This study showed that hearing screening by OAE yielded better results in terms of lower repeat and refers rates as well as a higher yield of the target condition.

\section{REFERENCES:}

1. Thompson DC, Mc Phillips H, Davis RL, Lieu TL, Homer CJ, Helfand M. Universal newborn hearing screening: summary of evidence. JAMA 2001; 286:2000-10.

2. Davis A, Bamford J, Wilson I, Ramkalawan T, Forshaw M, Wright S. A critical review of the role of neonatal hearing screening in the detection of congenital hearing impairment. Health Technol Assess 1997; 1: i-iv, 1-176.

3. Mehl AL, Thomson V. Newborn hearing screening: the great omission. Pediatrics 1998; 101:E4.

4. Kuhl PK, Williams KA, Lacerda F, Stevens KN, Lindblom B. Linguistic experience alters phonetic perception in infants by 6 months of age. Science 1992; 255:606-8.

5. Downs MP, Yoshinaga-Itano C. The efficacy of early identification and intervention for children with hearing impairment. Pediatr Clin North Am 1999; 46:79-87.

6. Sutton GJ, Scanlon PE. Health visitor screening versus vigilance: outcomes of programmes for detecting permanent childhood hearing loss in west Berkshire. Br J Audiol 1999;33:14556.

7. Brown J, Watson E, Alberman E. Screening infants for hearing loss. Arch Dis Child 1989; 64:1488-95.

8. Mott A, Emond A. What is the role of the distraction test of hearing? Arch Dis Child 1994; 70:10-3.

9. Davis A, Bamford J, Stevens J. Performance of neonatal and infant hearing screens: sensitivity and specificity. Br J Audiol 2001; 35:3-15.

10. Lutman ME. Techniques for neonatal hearing screening. Seminars in Hearing 2000; 21:36777.

11. Kemp DT, Ryan S. Otoacoustic emission tests in neonatal screening programmes. Acta Otolaryngol Suppl 1991; 482:73-84.

12. Vohr BR, Simon A, Letourneau K. Public health implications of universal hearing screening. Seminars in Hearing 2000; 21:295-307.

13. McCormick B. Diagnosing hearing problems in children. Curr Paediatr 2000; 10:200-5.

14. Department of Health. Piloting the introduction of universal neonatal screening in England. National Health Service Executive 2000; accessed at http://www.doh.gov.uk/uhnspilots/index.htm (2002 January 3).

15. Gorga MP, Neely ST, Ohlrich B, Hoover B, Redner J, Peters J. From laboratory to clinic: a large scale study of distortion product otoacoustic emissions in ears with normal hearing and ears with hearing loss. Ear Hear 1997; 18:440-55. 


\section{ORIGINAL ARTICLE}

Table: 1

\begin{tabular}{|l|l|l|}
\hline TEST & No of infants & Percentage \\
\hline PASS & 566 & $87.3 \%$ \\
\hline FAIL & 82 & $12.7 \%$ \\
\hline
\end{tabular}

Table: 2

\begin{tabular}{|l|l|l|}
\hline Condition & No of infants & Percentage \\
\hline Preterm with Hyperbilirubinemia & 22 & $26.8 \%$ \\
\hline Preterm with Respiratory distress & 14 & $17.07 \%$ \\
\hline Preterm/LBW & 17 & $20.73 \%$ \\
\hline Term & 29 & $35.36 \%$ \\
\hline
\end{tabular}

